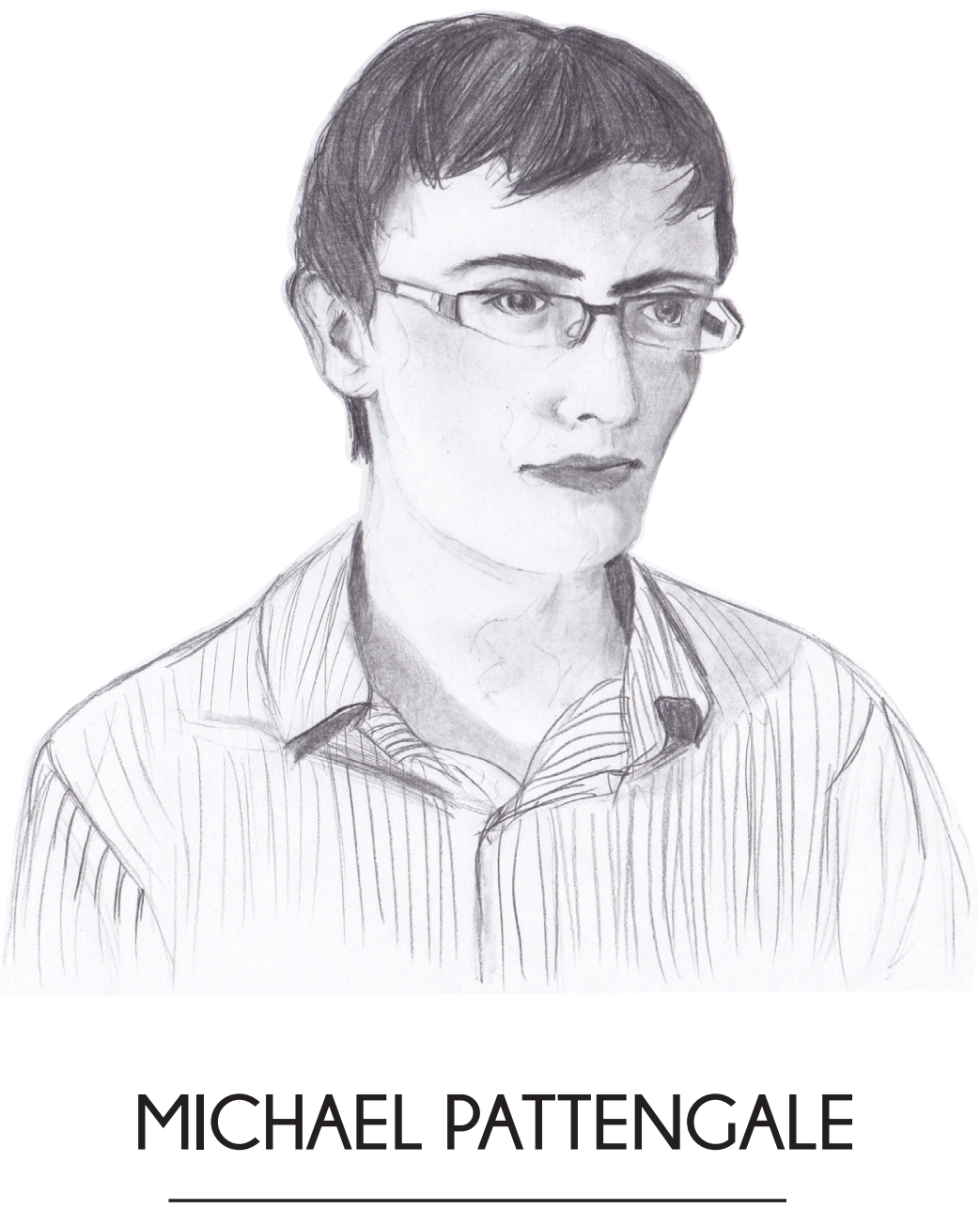

Michael Pattengale is a sophomore at Columbia College Chicago, studying Game Design. He enjoys writing stories, composing music, reading, learning, and getting the most out of every moment. Currently, Michael is living a peaceful college life, despite being in Chicago. 
FORBES \& FIFTH

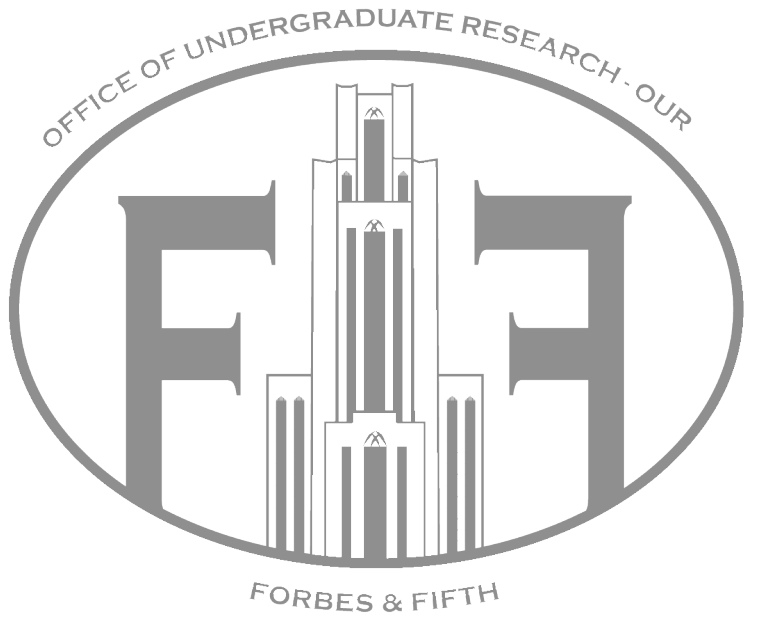




\section{Dear Sarah}

Dear Sarah,

I saw our grandson today. He is feeling much better than when I last saw him. In fact, when he saw me he jumped out of his bed and ran towards me. I was expecting him to jump up and wrap his arms around my waist, but instead, he put his hand into the shape of a gun and went, "Bang! Bang!" Of course I acted like I just got shot saying, "Ow! You got me!" but deep down I felt saddened. Not because he didn't immediately hug me - I understand his playful intentions. I think that it was the fact that he had discovered the gun and the purpose it serves. Although I doubt he can comprehend it, it reminds me of when I was his age. As you know, I was always fascinated by guns. I can't recall if I ever told you, but that's the reason I joined in the first place. The beauty and design mixed with remarkable power always captivated my attention. I hope he doesn't follow my footsteps. There's a reason I never told you, or anyone else those stories. Vivid imagination can't come up with what I've been through, with what I have seen.

That was not the first time I had to play dead.

The worst part is that there is no way I can stop him if he chooses that path. Even if I'm not dead or senile by the time he's of age, no story or logic can pull a man out of that desire. I know from experience. My father tried to snap me out of it. I wish I listened. It isn't for the light of heart. It changes people; it changed me. I guess, in a way, I am glad you never saw this changed man. You never got to see the man writing this letter. It is almost mocking. The same thing that made me who I am, the same thing that changed the man you knew, is what denied you the chance of seeing me. It denied me the chance of seeing you. It denied me the chance of saying goodbye. I may have been at the side of my friends as they fell, but I wasn't and will never get the chance to be there for you.

I am sorry.

I made a mistake, and I hope he doesn't make the same.

With love. 
FORBES \& FIFTH

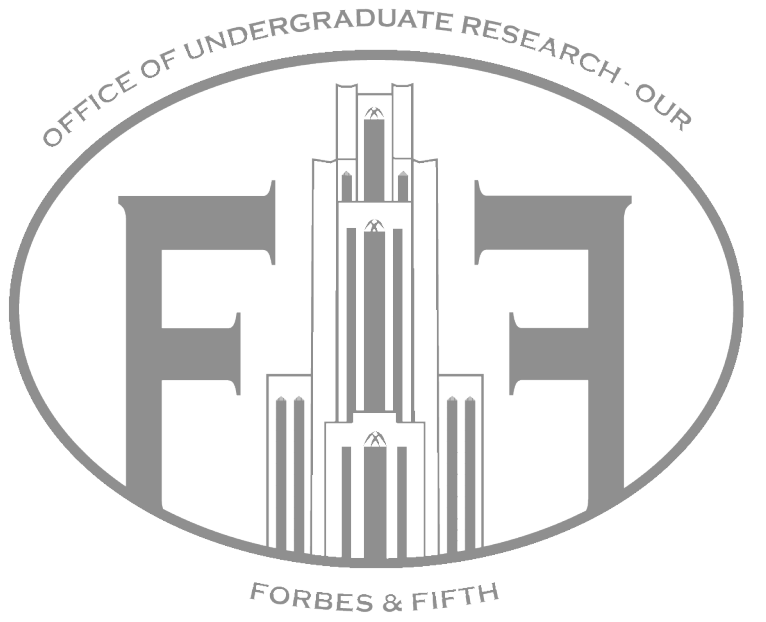

